\title{
The importance of the family for psychological symptomatology in a non-clinical population: expressed emotion and perceived maternal control
}

\author{
Duygu Cap ${ }^{1 \oplus}$, Ihsan Dag $^{2 \oplus}$ \\ 'Ufuk University, Faculty of Art and Science, Department of Psychology, Ankara - Turkey \\ ${ }^{2}$ Hacettepe University, Faculty of Art, Department of Psychology, Ankara - Turkey
}

\begin{abstract}
Objective: In this study, it was aimed to establish whether parental expressed emotion and perceived maternal psychological and behavioral control predict symptoms of depression, anxiety, and aggression and the level of general psychological symptomatology in healthy university students. Also, it was aimed to identify the type of relationships existing between the variables expressed emotion and perceived maternal control.

Method: Beck Depression, Beck Anxiety, Buss-Perry Aggression Inventories, Shortened Level of Expressed Emotion Scale in Adolescents, Psychological Control Scale-Youth Self Report, Parental Monitoring Scale" (mother forms), and a Sociodemographic Data Form were administered to 378 volunteer undergraduate students ( 260 females, 118 males) at a public university in Ankara.

Results: Results showed that expressed emotion and perceived maternal psychological control significantly predicted symptoms of depression, anxiety, and aggression and the level of psychological symptomatology positively, while maternal behavioral control significantly predicted aggression symptoms negatively. When all three variables were included, each one of them significantly predicted depressive symptoms. Maternal psychological and behavioral control significantly predicted anxiety symptoms. Expressed emotion and maternal psychological control significantly predicted aggression symptoms and expressed emotion significantly predicted the level of general psychological symptomatology.
\end{abstract}

Conclusion: The results of this study were largely consistent with the literature. For the first time in Turkey, we reported that expressed emotion predicted psychological symptomatology in a healthy population.

Keywords: Expressed emotion, general psychological symptomatology, perceived psychological control, perceived behavioral control.

\section{INTRODUCTION}

The importance of biological characteristics such as inheritance and psychosocial factors like early childhood experiences, education, upbringing, and family influence for our psychological well-being and in the etiology of mental disorders is well known. There is a great and ongoing interest in investigating the role of a person's family situation in this interaction between genes and the environment (1). Two of the most discussed concepts in the literature seeking an understanding of the family role are expressed emotion

How to cite this article: Cap D, Dag I. The importance of the family for psychological symptomatology in a non-clinical population: expressed emotion and perceived maternal control. Dusunen Adam The Journal of Psychiatry and Neurological Sciences 2019;32:246-258.

Correspondence: Duygu Cap, Ufuk University, Faculty of Art and Science, Department of Psychology, Ankara - Turkey

Phone: +90 3125867420 E-mail: duyguucap@gmail.com

Received: January 21, 2019; Revised: March 02, 2019; Accepted: July 04, 2019 
and parental control. Our study is based on these two concepts, investigating their predictive relationship with depressive, anxiety, and aggression symptoms and the level of general psychological symptomatology in a non-clinical university sample.

While expressed emotion (EE) has been studied since the 1950s, it has mostly been identified with family members' attitude, emotion, and behaviors projected on the sick person $(2,3)$. Though the concept also entails positive traits like warmth and intimacy, it generally includes negative states (4), which have been expressed in dimensions like criticism, hostile attitude, and emotional over involvement. Criticism is defined as negative remarks about the sick person, marked by tone of voice and speech content, and by being made overly uncomfortable by the sufferer (5). Hostile attitude, rather than being a particular behavior, involves a general negative attitude against the ill person. Therefore, patient relatives may find it difficult to control their anger towards the sick person, whom they might consider the source of their problems. Emotional over involvement can lead to situations where family members devote themselves for the patient, assume responsibility for day-to-day events, and are unable to look at the situation objectively (3). A review article addressing the relations between various psychological disorders and health problems and EE revealed that in a number of psychological disorders such as depression, eating disorders, post-traumatic stress disorder, addictions, personality disorders, and agoraphobia, high EE had a negative effect on the duration of recurrence, course of the disease, severity of symptoms, and response to treatment (6). There are relatively few studies about EE in non-clinical samples, and the existing ones usually look at childhood or adolescence. First of all, in families with high EE, the probability to have any psychological symptoms was found to be five times higher than in families with low EE (7). A study with mothers and daughters determined that maternal depression symptoms predicted depressive symptoms in the children, which was mediated by criticism (8). Similarly, other studies also found an elevated level of psychological symptoms in children of mothers with a high level of criticism due to EE (9-11). Regarding the subdimensions of EE, a study including mothers and children showed that while a more critical attitude was related with higher internalized (depression, anxiety) and externalized (aggression) psychological symptoms, emotional over-involvement also had a protective effect against externalized symptoms (aggression) (11). A study with middle school students found that all subdimensions were positively correlated with psychological symptoms (12). In sum, while findings suggest that there might be a positive effect of some subdimensions, most conclude that high $\mathrm{EE}$ is a risk factor for psychological symptoms.

Similar to EE, parental control is another concept emphasizing family traits that is thought to affect psychological symptoms (13). This concept includes a number of dimensions: behaviors such as guilt induction, love withdrawal, make persons feel ashamed, and limit their independence, or situations like supervision, control, and awareness of their behaviors (14). Therefore, measures to control the child's behaviors, actions, thoughts, and feelings are seen to be evaluated from 2 perspectives (15). Under psychological control (PC), parents control children's behavior more indirectly, by passive-aggressive means, thus affecting children's self-expression, thinking processes, attachment to parents, and emotions-particularly by inhibiting individuals' autonomy during and after adolescence (14-16). In the literature, a positive correlation between PC and psychological symptoms as well as behavioral problems has been reported (14). Under behavioral control (BC), parents control children's behaviors with more direct methods such as disciplining and supervision. Parents pose the child various conditions, applying control to ensure that children follow these conditions, knowing when they did what where and with whom (15,17-19). In contrast to $\mathrm{PC}, \mathrm{BC}$ attempts to change and control behaviors rather than emotion and thinking processes, which has been found to be related with higher academic success, life satisfaction, and self-confidence and with a lower level of behavioral problems $(15,20,21)$.

A study on PC in mothers and daughters found that high perceived maternal PC predicted internalized symptoms such as depressive and anxiety symptoms in their daughters (17). Similarly, PC was seen to predict higher depressive symptoms in adolescents (23). A multicultural study seeking cultural differences of this effect, enrolling 14-17-year-old adolescents from South Africa, Bangladesh, China, India, Bosnia, Palestine, Germany, the USA, and Columbia found this effect to be almost universal, perceived maternal PC predicting depression symptoms (24). Two studies investigating externalized symptoms in children and adolescents found that for both sexes, high perceived maternal PC predicted externalized symptoms such as overt, social, and relational aggression $(25,26)$. Regarding sex differences, one study found that high PC did not predict aggression symptoms in male children, while its 
prediction of physical aggression in girls almost reached significance level (27). Among studies with Turkish samples, one paper reported that high perceived maternal PC correlated with externalized symptoms like aggression and internalized symptoms like loneliness (28); another study found correlations for internalized as well as externalized symptoms in girls, while in boys only externalized symptoms correlated (22).

Studies on BC are even scarcer and limited to mothers, which further decreases the amount of available research. In contrast with the negative effects of PC, studies indicate that BC may have a positive impact on individuals. A study with an Afro-American sample showed that perceived maternal BC was not correlated with depressive symptoms, while there was a significant negative correlation with delinquency (21). Another study found a negative prediction for physical and relational aggression in boys but no significant correlation in girls (28). One study with a Turkish sample found a negative correlation between perceived maternal $\mathrm{BC}$ and internalized as well as externalized symptoms in boys (22); by contrast, another study found that in girls having a deviant friend and bullying were reduced, while there was no significant difference in boys (15). In sum, it can be said that high perceived maternal PC predicts higher internalized (depressive, anxiety, loneliness) and externalized (aggression) symptoms; the correlation of BC with externalized symptoms is negative, while results for internalized symptoms may vary, mainly according to sex.

Our study examines the predictive correlation of $\mathrm{EE}$ and perceived maternal PC and BC, two concepts that are similar in some respects, with depressive, anxiety, aggression symptoms, and the level of general psychological symptomatology (LGPS) in a nonclinical university sample. While it is known that the family environment is important for a person's wellbeing, EE has been mainly studied in psychiatric samples or, when in non-clinical samples, mainly with children and adolescents; it appears therefore important that our study is carried out in a nonclinical adult sample to establish this effect in healthy adults. The other concept, parental control, also has been studied mainly in children and adolescents; however, it is known that parental control continues for university students, albeit to a lesser extent (29). Therefore, our study contributes to an understanding of the impact of control on adults. Even if the behaviors measured with these approaches are similar, we could not find either in the Turkish or in the international literature any research addressing EE and perceived maternal control together, which should be relevant for us to be able to see the whole picture.

\section{METHOD}

The study sample consisted of 378 volunteer students from a State university in Ankara from the 1st to the $6^{\text {th }}$ year $\left(1^{\text {st }}\right.$ year: $36.8 \%, 2^{\text {nd }}$ year: $30.2 \%, 3^{\text {rd }}$ year: $18.5 \%, 4^{\text {th }}$ year: $10.6 \%, 5^{\text {th }}$ year: $1.9 \%$, and $6^{\text {th }}$ year: $\left.2.1 \%\right)$, studying psychology $(34.7 \%)$, sociology (19\%), family and consumer sciences $(17.2 \%)$, automotive engineering (7.9\%), philosophy (7.7\%), civil engineering (4.5\%), and other subjects (9\%); they had no psychiatric diagnoses and had not lost their mother. Their age range was 17-29 years (mean $[\mathrm{M}]=20.26$; standard deviation $[\mathrm{SD}]=1.78), 260$ were female $(68.8 \%)$ and 118 male $(31.2 \%)$. Most participants were from a middle-income background (62.7\%), the maternal education level in $80 \%$ and the paternal education level in $65.1 \%$ was high school or below, and in $96.3 \%$ of the participants, the father was still alive.

\section{Measures}

Sociodemographic Data Form: This form was prepared by the researchers, recording information such as participants' age, sex, subject and year of study, accommodation, income level, presence of psychiatric disorders, parents' education levels, and if they were alive. This article only reports the sociodemographic data relevant to the analysis; the remaining data are presented in their entirety in the thesis version (30).

Beck Depression Inventory (BDI): This instrument was developed by Beck (31) and adapted to Turkish by Hisli (32) to evaluate cognitive, emotional, and motivational symptoms commonly found in depression; it consists of 21 items. The adapted form has a split-half test reliability coefficient of 0.74 and a criterion-related validity coefficient in the range of 0.47-0.63. The adaptation study found an internal consistency coefficient of 0.80 , while in our study it was 0.84 .

Beck Anxiety Inventory (BAI): Developed by Beck et al. (33), the scale measuring the frequency of various anxiety symptoms consisting of 21 items was adapted to Turkish by Sahin and Erkmen (34). Each item is scored between 0 and 3 points $(0=$ not at all, $1=$ mildly, $2=$ moderately, $3=$ severely), with a total score from 0-63 points. In the adaptation, the test-retest reliability 
coefficient was 0.57 , the criterion-related validity coefficient was 0.46 with the BDI and between 0.45 and 0.53 with the State-Trait Anxiety Inventory. Internal consistency of the scale in a clinical sample was 0.93 , while in the present study, it was 0.88 .

Brief Symptom Inventory (BSI): Developed by Derogatis (35) and adapted to Turkish by Sahin and Durak (36), this instrument consisting of 53 items measures various psychological symptoms. Being scored between 0 and $4(0=$ not at all, $1=$ somewhat, $2=$ moderately, $3=$ quite a bit, $4=$ extremely), the total score is between 0 and 212. The instrument includes 5 subdimensions: anxiety, depression, negative self, somatization, and hostility. Its validity was found to be between 0.13 and 0.36 with the UCLA Loneliness Scale, 0.34-0.70 with the BDI, and 0.16-0.42 with the Submissive Behavior Scale. Internal consistency coefficients were between 0.95 and 0.96 ; in the present study, it was 0.95 for the entire scale.

Buss-Perry Aggression Questionnaire (BPAQ): This instrument was developed by Buss and Perry (37) and adapted to Turkish by Demirtas-Madran (38). The items are scored on a five-point Likert-type scale (extremely uncharacteristic of me to extremely characteristic of me). The scale consists of 29 items in 4 subdimensions: physical and verbal aggression, hostility, and anger. Items 9 and 16 are reverse-scored. Cronbach's alpha for the total scale was 0.97 in the adaptation study and 0.88 in the present work.

Shortened Level of Expressed Emotion Scale in Adolescents (SLEES): This scale was developed by Nelis et al. (39) and adapted to Turkish by Vural et al. (40). It consists of 33 items scored on a 4-point Likerttype scale (not true; mostly untrue; mostly true; true). Items 1-15 and items 31 and 33 are reverse-scored. The instrument consists of the subdimensions Lack of Emotional Support, Irritability, and Intrusiveness. To establish the validity of the measure, the "anger" dimension of the Multidimensional Anger Scale was used, finding a correlation of 0.49 . Cronbach's alpha was 0.90 in the adaptation study and 0.91 in the present work.

Psychological Control Scale (mother form) (PCS): Developed by Barber et al. (41), this instrument was adapted to Turkish by Sayil and Kindap (42). It measures the psychological control exerted by parents over adolescents. The scale consists of 8 items scored on a 4-point Likert-type scale (1-not at all like my mother; 4 -very much like my mother). Construct validity showed a 2-factor structure (psychological control and parental disrespect). In its validity, perceived psychological control and parental disrespect were negatively correlated with democratic parenting style and positively with authoritarian type. Cronbach's alpha in the adaptation study was 0.85 , in the present study 0.73 .

Parental Monitoring Scale (mother form) (PMS): The instrument was developed by Kerr and Stattin (15) and adapted to Turkish by Sayil et al. (43) to assess perceived parental behavioral control. It consists of 8 items scored on a 5-point Likert-type scale (1-never know; 5-always know). The construct validity of the scale, with principal component analysis resulting in a Kaiser-Meyer-Olkin (KMO) value of 0.79 and an eigenvalue above 1 , found a 1 -factor structure. The internal consistency coefficient in the adaptation study was 0.80 and in the present work 0.90 .

\section{Procedure}

With the approval of the ethics committee of Hacettepe University, data were collected from October 2016 to January 2017. While the sociodemographic form was always completed first, the other instruments were administered in random order. Before the administration, participants were informed verbally and in a written way without compromising the measurement. After receiving the student volunteers' consent, data were collected in a classroom setting collectively by the researcher. Completing the scales took around 30 minutes.

\section{Statistical Analysis}

After data collection, forms were numbered and replies coded with SPSS 22.0. Before the analyses, data entries were checked; data for participants meeting exclusion criteria (psychiatric disorder, loss of mother) or leaving more than $10 \%$ of the items blank were not included in the analysis. Subsequently, missed values and outliers were scanned. Finally, normality was assessed by evaluating skewness and kurtosis values; the skewness-kurtosis values obtained for the basic variables being between -1 and +1 , it was decided to use parametric tests in the study (44) (see Table 1). All data included in the analysis were assessed as a whole, and to answer the research questions, regression and hierarchical regression analyses were carried out (Table 1).

\section{RESULTS}

Descriptive statistics for all continuous variables in the study are presented in Table 2. In line with the study 
Table 1: Kurtosis and skewness values for the basic continuous variables in this study

\begin{tabular}{lccccc} 
Instrument & $\mathbf{N}$ & Skewness & Standard error & Kurtosis & Standard error \\
\hline SLEES & 398 & 0.95 & 0.12 & 0.89 & 0.24 \\
PMS & 398 & -0.23 & 0.12 & -0.37 & 0.24 \\
PCS & 398 & 0.98 & 0.12 & 0.85 & 0.24 \\
BDI & 398 & 0.83 & 0.12 & 0.29 & 0.24 \\
BAI & 398 & 0.95 & 0.12 & 0.69 & 0.24 \\
BPAQ & 398 & 0.33 & 0.12 & -0.08 & 0.24 \\
$\quad$ PHYSAG & 398 & 0.74 & 0.12 & -0.00 & 0.24 \\
$\quad$ ANGER & 398 & 0.23 & 0.12 & -0.54 & 0.24 \\
$\quad$ HOST & 398 & 0.07 & 0.12 & -0.36 & 0.24 \\
$\quad$ VERBAG & 398 & 0.25 & 0.12 & 0.18 & 0.24 \\
BSI & 398 & 0.95 & 0.12 & 0.73 & 0.24 \\
\hline
\end{tabular}

N: Number of participants, SLEES: Shortened Level of Expressed Emotion Scale in Adolescents, PMS: Parental Monitoring Scale (Behavioral control-mother), PCS: Psychological Control Scale (Anne), BDI: Beck Depression Inventory, BAI: Beck Anxiety Inventory, BPAQ: Buss-Perry Aggression Questionnaire, PHYSAG: Physical aggression subdimension, ANGER: Anger subdimension, HOST: Hostility subdimension, VERBAG: Verbal aggression subdimension, BSI: Brief Symptom Inventory

Table 2: Descriptive statistics of the basic continuous variables in this study

\begin{tabular}{lcccc} 
Instrument & $\mathbf{N}$ & Mean & Standard deviation & Range \\
\hline SLEES & 378 & 58.33 & 13.51 & $34-104$ \\
PMS & 378 & 25.79 & 6.82 & $8-40$ \\
PCS & 378 & 12.77 & 3.68 & $8-25$ \\
BDI & 378 & 10.40 & 7.09 & $0-35$ \\
BAI & 378 & 11.21 & 8.39 & $0-38$ \\
BPAQ & 378 & 73.52 & 16.30 & $32-118$ \\
\multicolumn{1}{c}{ PHYSAG } & 378 & 18.35 & 6.15 & $9-35$ \\
\multicolumn{1}{c}{ ANGER } & 378 & 18.36 & 5.88 & $7-32$ \\
\multicolumn{1}{r}{ VERBAG } & 378 & 22.62 & 5.72 & $8-37$ \\
BSI & 378 & 14.19 & 3.56 & $5-25$ \\
\hline
\end{tabular}

N: Number of participants, SLEES: Shortened Level of Expressed Emotion Scale in Adolescents, PMS: Parental Monitoring Scale (Behavioral control-mother), PCS: Psychological Control Scale (Anne), BDI: Beck Depression Inventory, BAl: Beck Anxiety Inventory, BPAQ: Buss-Perry Aggression Questionnaire, PHYSAG: Physical aggression subdimension, ANGER: Anger subdimension, HOST: Hostility subdimension, VERBAG: Verbal aggression subdimension, BSI: Brief Symptom Inventory

aims, first of all Pearson correlation analysis as the basis for regression analysis showing the correlations between all continuous variables of the study is presented in Table 3. In this paper, perceived maternal PC has been abbreviated as PC and perceived maternal $\mathrm{BC}$ as BC (Table 2, Table 3).

Results regarding the prediction of depressive, anxiety, aggression symptoms, subdimensions of aggression, and the level of general psychological symptomatology by EE are summarized in Table 4 .

According to the results of regression analysis, EE significantly and positively predicted depressive $\left(\mathrm{F}_{1.376}=16.64, \mathrm{p}<0.01, \mathrm{R}^{2}=0.04\right)$, anxiety $\left(\mathrm{F}_{1.376}=9.49\right.$, $\left.\mathrm{p}<0.01, \mathrm{R}^{2}=0.03\right)$, general aggression symptoms
$\left(\mathrm{F}_{1.376}=25.27, \mathrm{p}<0.01, \mathrm{R}^{2}=0.06\right)$ and the aggression subdimensions physical aggression $\left(\mathrm{F}_{1.376}=23.34\right.$, $\left.\mathrm{p}<0.01, \mathrm{R}^{2}=0.06\right)$, anger $\left(\mathrm{F}_{1.376}=10.40, \mathrm{p}<0.05, \mathrm{R}^{2}=0.03\right)$, hostility $\left(\mathrm{F}_{1.376}=12.39, \mathrm{p}<0.01, \mathrm{R}^{2}=0.03\right)$, and verbal aggression symptoms $\left(\mathrm{F}_{1.376}=11.66, \mathrm{p}<0.05, \mathrm{R}^{2}=0.03\right)$ and level of general psychological symptomatology $\left(\mathrm{F}_{1.376}=16.20, \mathrm{p}<0.01, \mathrm{R}^{2}=0.04\right)$.

\section{Results for the prediction of psychological symptoms by perceived maternal control}

As seen in Table 4, according to the results of regression analysis for the predictive relation between PC and BC and depressive, anxiety, aggression symptoms, and level of general psychological symptomatology, PC 


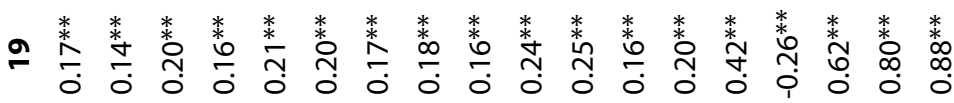

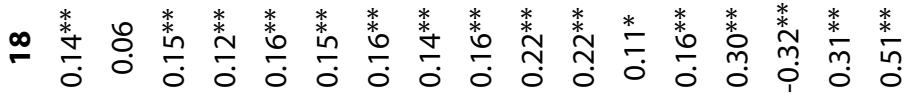

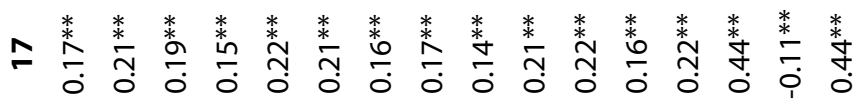

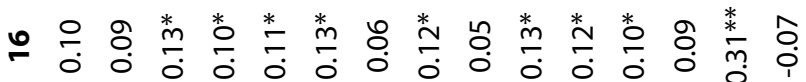

n

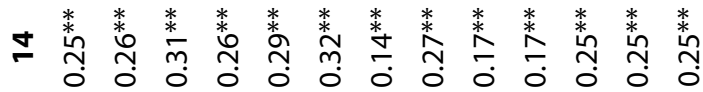

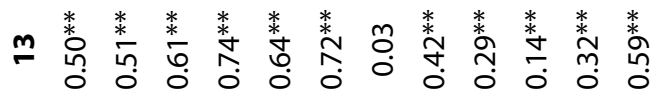

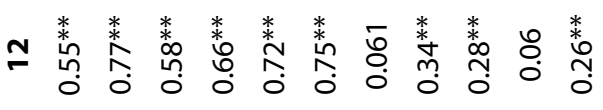

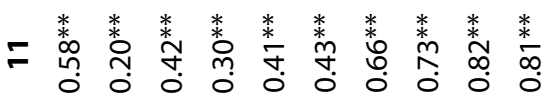

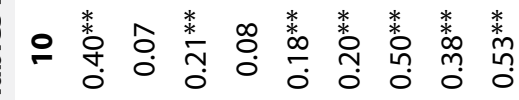

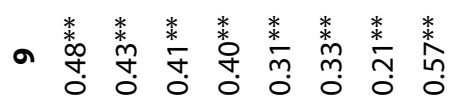

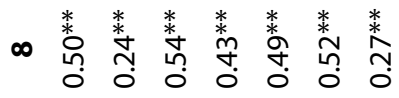

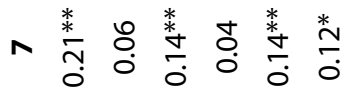

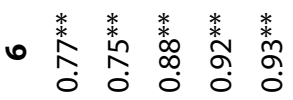

in $\begin{array}{llll}* & * & * & * \\ 0 & 0 & * & * \\ 0 & 0 & 0 \\ 0 & 0 & 0 & 0 \\ 0 & 0\end{array}$

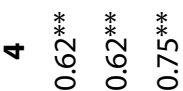

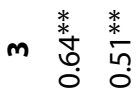

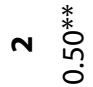

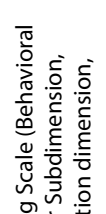

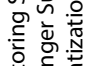




\begin{tabular}{|c|c|c|c|c|c|c|}
\hline Dependent variable & Predictor variable & $\mathbf{R}$ & $\mathbf{R}^{2}$ & B & $\mathbf{t}$ & $\mathbf{p}$ \\
\hline BDI & SLEES & 0.20 & 0.04 & 0.20 & 3.96 & $<0.001$ \\
\hline BAI & SLEES & 0.16 & 0.03 & 0.16 & 3.08 & 0.002 \\
\hline BPAQ & SLEES & 0.25 & 0.06 & 0.25 & 5.03 & $<0.001$ \\
\hline PHYSAG & SLEES & 0.24 & 0.06 & 0.24 & 4.83 & $<0.001$ \\
\hline ANGER & SLEES & 0.16 & 0.03 & 0.16 & 3.22 & 0.001 \\
\hline HOST & SLEES & 0.18 & 0.03 & 0.18 & 3.52 & $<0.001$ \\
\hline VERBAG & SLEES & 0.17 & 0.03 & 0.17 & 3.42 & 0.001 \\
\hline BSI & SLEES & 0.20 & 0.04 & 0.20 & 4.03 & $<0.001$ \\
\hline BDI & PCS & 0.25 & 0.06 & 0.25 & 5.04 & $<0.001$ \\
\hline BAI & PCS & 0.25 & 0.06 & 0.25 & 4.89 & $<0.001$ \\
\hline BPAQ & PCS & 0.25 & 0.06 & 0.25 & 4.97 & $<0.001$ \\
\hline PHYSAG & PCS & 0.17 & 0.03 & 0.17 & 3.29 & 0.001 \\
\hline ANGER & PCS & 0.17 & 0.03 & 0.17 & 3.27 & 0.001 \\
\hline HOST & PCS & 0.27 & 0.07 & 0.27 & 5.44 & $<0.001$ \\
\hline VERBAG & PCS & 0.14 & 0.03 & 0.14 & 2.76 & 0.006 \\
\hline BSI & PCS & 0.32 & 0.10 & 0.32 & 6.48 & $<0.001$ \\
\hline BDI & PMS & 0.04 & 0.00 & 0.04 & 0.70 & 0.485 \\
\hline BAI & PMS & 0.07 & 0.01 & 0.07 & 1.34 & 0.182 \\
\hline BPAQ & PMS & 0.17 & 0.03 & -0.17 & -3.35 & 0.001 \\
\hline PHYSAG & PMS & 0.23 & 0.05 & -0.23 & -4.52 & $<0.001$ \\
\hline ANGER & PMS & 0.08 & 0.01 & -0.08 & -1.57 & 0.118 \\
\hline HOST & PMS & 0.05 & 0.00 & -0.05 & -1.04 & 0.298 \\
\hline VERBAG & PMS & 0.17 & 0.03 & -0.17 & -3.32 & 0.001 \\
\hline BSI & PMS & 0.05 & 0.00 & -0.05 & -0.10 & 0.319 \\
\hline
\end{tabular}

SLEES: Shortened Level of Expressed Emotion Scale in Adolescents, PMS: Parental Monitoring Scale (Behavioral control), PCS: Psychological Control Scale, BDI: Beck Depression Inventory, BAI: Beck Anxiety Inventory, BPAQ: Buss-Perry Aggression Questionnaire, PHYSAG: Physical Aggression Subdimension, ANGER: Anger Subdimension, HOST: Hostility Subdimension, VERBAG: Verbal Aggression Subdimension, BSI: Short Symptom Inventory

significantly and positively predicted depressive symptoms $\left(\mathrm{F}_{1.376}=25.38, \mathrm{p}<0.01, \mathrm{R}^{2}=0.06\right)$, anxiety $\left(\mathrm{F}_{1.376}=23.94, \mathrm{p}<0.01, \mathrm{R}^{2}=0.06\right)$, general aggression symptoms $\left(\mathrm{F}_{1.376}=24.73, \mathrm{p}<0.01, \mathrm{R}^{2}=0.06\right)$, and the subdimensions physical $\left(\mathrm{F}_{1376}=10.80, \mathrm{p}<0.05, \mathrm{R}^{2}=0.03\right)$ and verbal aggression $\left(\mathrm{F}_{1,376}=7.59, \mathrm{p}<0.05, \mathrm{R}^{2}=0.07\right)$, anger $\left(\mathrm{F}_{1.376}=10.68, \mathrm{p}<0.05, \mathrm{R}^{2}=0.03\right)$, and hostility $\left(\mathrm{F}_{1.376}=29.54, \mathrm{p}<0.01, \mathrm{R}^{2}=0.07\right)$ symptoms and the level of general psychological symptomatology $\left(\mathrm{F}_{1.376}=42.04\right.$, $\left.\mathrm{p}<0.01, \mathrm{R}^{2}=0.10\right)$.

However, $\mathrm{BC}$ was found not to predict individuals' depressive $\left(\mathrm{F}_{1,376}=0.49, \mathrm{p}>0.05\right)$, anxiety symptoms $\left(\mathrm{F}_{1.376}=1.79, \mathrm{p}>0.05\right)$, and level of general psychological symptomatology $\left(\mathrm{F}_{1.376}=1.00, \mathrm{p}>0.05\right)$. The aggression subdimensions physical $\left(\mathrm{F}_{1.376}=20.45, \mathrm{p}<0.01, \mathrm{R}^{2}=0.05\right)$ and verbal aggression symptoms $\left(\mathrm{F}_{1376}=11.01, \mathrm{p}<0.05\right.$, $\left.\mathrm{R}^{2}=0.03\right)$ were predicted significantly and negatively, while anger $\left(\mathrm{F}_{1.376}=2.46, \mathrm{p}>0.05\right)$ and hostility symptoms $\left(\mathrm{F}_{1376}=1.08, \mathrm{p}>0.05\right)$ were not predicted.

Results of hierarchical regression analysis for the correlations between expressed emotion and psychological and behavioral control variables

As we could not find any study in the literature treating $\mathrm{EE}$ and control variables together, we included these variables into the model, considering the level of correlation between predictor variable and dependent variable for the hierarchical regression analysis of the correlations between $\mathrm{EE}, \mathrm{PC}$, and $\mathrm{BC}$ regarding psychological symptoms. Accordingly, variables were included in the analysis, beginning with the most highly correlated variable and proceeding in order to the variable with the lowest correlations. Results of the hierarchical regression analysis are summarized in 
Table 5. As the joint evaluation of all predictor variables was important for our study, the first and second steps of the hierarchical regression analysis are not presented in the table (Table 5).

The contribution of PC, which was entered in the first block for depressive symptoms, was found to be significant $\left(\mathrm{F}_{1.376}=25.38, \mathrm{p}<0.01, \mathrm{R}^{2}=0.06\right)$, predicting depressive symptoms significantly $(\beta=0.25, p<0.01)$. In the second block, $\mathrm{BC}$ was added to the model and a significant contribution of this variable to the model was found $\left(\mathrm{F}_{2.375}=14.44, \mathrm{p}<0.01\right)$. While PC predicted depressive symptoms $(\beta=0.27, \mathrm{p}<0.01)$, it was seen that after controlling for $\mathrm{PC}, \mathrm{BC}$ did not predict depressive symptoms ( $\beta=0.09, p>0.05)$. Variance explained in the second step increased to $7 \%$, but this contribution of $1 \%$ was not found to be statistically significant $\left(\mathrm{R}^{2}=0.07\right.$,

Table 5: Results of hierarchical regression analysis for the correlations between expressed emotion and perceived maternal control (psychological and behavioral control) regarding psychological symptoms

\begin{tabular}{|c|c|c|c|c|c|c|c|c|c|}
\hline Dependent variable & $\begin{array}{l}\text { Predictor } \\
\text { variable }\end{array}$ & $\mathbf{F}$ & $\mathbf{R}$ & $\mathbf{R}^{2}$ & $\Delta \mathbf{R}^{2}$ & $\mathbf{F}_{\text {change }}$ & B & SHB & В \\
\hline \multirow[t]{4}{*}{ Depressive symptoms } & & $11.79^{* *}$ & 0.30 & 0.09 & $0.02^{* *}$ & $6.01^{*}$ & & & \\
\hline & SLEES & & & & & & 0.42 & 0.11 & 0.22 \\
\hline & PCS & & & & & & 0.12 & 0.05 & 0.12 \\
\hline & PMS & & & & & & 0.07 & 0.03 & 0.14 \\
\hline \multirow[t]{4}{*}{ Anxiety symptoms } & & $11.12^{* *}$ & 0.29 & 0.08 & 0.007 & $2.82^{* *}$ & & & \\
\hline & PCS & & & & & & 0.54 & 0.13 & 0.24 \\
\hline & PMS & & & & & & 0.18 & 0.06 & 0.14 \\
\hline & SLEES & & & & & & 0.06 & 0.04 & 0.09 \\
\hline \multirow[t]{4}{*}{ General aggression symptoms } & & $13.25^{* *}$ & 0.31 & 0.10 & 0.01 & 3.53 & & & \\
\hline & SLEES & & & & & & 0.19 & 0.07 & 0.16 \\
\hline & PCS & & & & & & 0.71 & 0.24 & 0.16 \\
\hline & PMS & & & & & & -0.23 & 0.12 & -0.01 \\
\hline \multirow[t]{4}{*}{ Physical aggression symptoms } & & $12.38^{* *}$ & 0.30 & 0.09 & 0.003 & 1.09 & & & \\
\hline & SLEES & & & & & & 0.08 & 0.03 & 0.17 \\
\hline & PMS & & & & & & -0.15 & 0.05 & -0.17 \\
\hline & PCS & & & & & & 0.10 & 0.09 & 0.06 \\
\hline \multirow[t]{4}{*}{ Anger symptoms } & & $5.06^{* *}$ & 0.20 & 0.04 & 0.001 & 0.30 & & & \\
\hline & PCS & & & & & & 0.18 & 0.09 & 0.11 \\
\hline & SLEES & & & & & & 0.05 & 0.03 & 0.11 \\
\hline & PMS & & & & & & -0.03 & 0.05 & -0.03 \\
\hline \multirow[t]{4}{*}{ Hostility symptoms } & & $10.57^{* *}$ & 0.28 & 0.08 & 0.000 & 0.12 & & & \\
\hline & PCS & & & & & & 0.37 & 0.09 & 0.24 \\
\hline & SLEES & & & & & & 0.04 & 0.02 & 0.08 \\
\hline & PMS & & & & & & 0.02 & 0.04 & -0.02 \\
\hline \multirow[t]{4}{*}{ Verbal aggression symptoms } & & $6.59^{* *}$ & 0.22 & 0.05 & 0.004 & 1.39 & & & \\
\hline & SLEES & & & & & & 0.03 & 0.02 & 0.11 \\
\hline & PMS & & & & & & -0.07 & 0.03 & -0.13 \\
\hline & PCS & & & & & & 0.06 & 0.05 & 0.07 \\
\hline \multirow[t]{4}{*}{$\begin{array}{l}\text { Level of general psychological } \\
\text { symptomatology }\end{array}$} & & $14.98^{* *}$ & 0.33 & 0.11 & 0.001 & 0.39 & & & \\
\hline & PCS & & & & & & 2.12 & 0.40 & 0.29 \\
\hline & SLEES & & & & & & 0.18 & 0.11 & 0.09 \\
\hline & PMS & & & & & & 0.13 & 0.20 & 0.03 \\
\hline
\end{tabular}

${ }^{*} p<0.05,{ }^{* *} p<0.001$. SLEES: Shortened Level of Expressed Emotion Scale in Adolescents, PMS: Parental Monitoring Scale (Behavioral control) Mother form, PCS: Psychological Control Scale mother form 
$\left.\Delta \mathrm{F}_{1.375}=3.34, \mathrm{p}>0.05\right)$. In the third block, EE was added to the model and a significant contribution to the model was found for this variable $\left(\mathrm{F}_{3.374}=11.79, \mathrm{p}<0.01\right)$. At this point, it was seen that these 3 variables significantly predicted depressive symptoms $\left(\beta_{\mathrm{PCS}}=0.22, \mathrm{p}<0.01\right.$; $\left.\beta_{\mathrm{PMS}}=0.12, \mathrm{p}<0.05 ; \beta_{\mathrm{SLEES}}=0.14, \mathrm{p}<0.05\right)$. Variance explained increased to $9 \%$, and this change in variance of $2 \%$ was significant $\left(\mathrm{R}^{2}=0.09, \Delta \mathrm{F}_{1.374}=6.01, \mathrm{p}<0.05\right)$.

The contribution of PC to the model, added for anxiety symptoms, was significant $\left(\mathrm{F}_{1.376}=23.92\right.$, $\mathrm{p}<0.01)$, predicted anxiety symptoms significantly $(B=0.25, p<0.01)$, and explained $6 \%$ of the variance in correlation $\left(\mathrm{R}^{2}=0.06\right)$. In the second block, $\mathrm{BC}$ was added to the model and a significant contribution to the model was found $\left(\mathrm{F}_{2.375}=15.93, \mathrm{p}<0.01\right)$. After controlling for $\mathrm{PC}, \mathrm{BC}$ was seen to predict anxiety symptoms $\left(B_{\mathrm{PMS}}=0.13, \mathrm{p}<0.05\right)$. With the added variable, variance explained increased to $8 \%$, and the contribution of $2 \%$ was found to be statistically significant $\left(\mathrm{R}^{2}=0.08, \Delta \mathrm{F}_{1.375}=6.14, \mathrm{p}<0.05\right)$. In the third block, EE was added to the model and a significant contribution of this variable to the model was found $\left(\mathrm{F}_{3.374}=11.12, \mathrm{p}<0.01\right)$. After controlling for $\mathrm{PC}$ and $\mathrm{BC}$, it was seen that $\mathrm{EE}$ did not predict anxiety symptoms at a significant level $\left(\beta_{\mathrm{PCS}}=0.24, \mathrm{p}<0.01 ; \beta_{\mathrm{PMS}}=0.14, \mathrm{p}<0.05\right.$; $\left.\beta_{\text {SLEES }}=0.09, p>0.05\right)$. Variance explained increased to $8.2 \%$, but this change was not significant $\left(\mathrm{R}^{2}=0.082\right.$, $\left.\Delta \mathrm{F}_{1.374}=2.82, \mathrm{p}>0.05\right)$.

When EE was added to the model in the first block for general aggression symptoms, the contribution to the model was significant $\left(\mathrm{F}_{1.376}=25.27, \mathrm{p}<0.01\right)$, general aggression symptoms were predicted significantly $(B=0.25, p<0.01)$, and $6 \%$ of variance in correlation was explained $\left(\mathrm{R}^{2}=0.06\right)$. In the second block, $\mathrm{PC}$ was added to the model and its contribution to the model was significant $\left(\mathrm{F}_{2.375}=17.99, \mathrm{p}<0.01\right)$. After controlling for EE, $P C$ predicted general aggression symptoms $(B=0.17$, $\mathrm{p}<0.05)$. Variance explained increased to $9 \%$ and this contribution of $3 \%$ was statistically significant $\left(\mathrm{R}^{2}=0.09\right.$, $\left.\Delta \mathrm{F}_{1.375}=10.10, \mathrm{p}<0.05\right)$. In the third block, $\mathrm{BC}$ was added to the model and its contribution to the model was found significant $\left(\mathrm{F}_{3.374}=13.25, \mathrm{p}<0.01\right)$. After controlling for $\mathrm{EE}$ and $\mathrm{PC}$, it was seen that $\mathrm{BC}$ did not predict general aggression symptoms at a significant level $\left(\beta_{\text {SLEES }}=0.16, \mathrm{p}<0.01 ; \beta_{\mathrm{PCS}}=0.16, \mathrm{p}<0.01 ; \beta_{\mathrm{PMS}}=-0.01\right.$, $\mathrm{p}>0.05)$. Variance explained increased to $10 \%$ and this $1 \%$ change was not found to be significant $\left(\mathrm{R}^{2}=0.10\right.$, $\left.\Delta \mathrm{F}_{1.374}=3.53, \mathrm{p}>0.05\right)$

When EE was added to the model in the first block for physical aggression symptoms, its contribution to the model was significant $\left(\mathrm{F}_{1.376}=23.34, \mathrm{p}<0.01\right)$, it predicted physical aggression symptoms significantly $(B=0.24, p<0.01)$, and $6 \%$ of variance in correlation was explained $\left(\mathrm{R}^{2}=0.06\right)$. In the second block, $\mathrm{BC}$ was added to the model and its contribution to the model was significant $\left(\mathrm{F}_{2375}=18.03, \mathrm{p}<0.01\right)$. After controlling for $\mathrm{EE}$, it was seen that $\mathrm{BC}$ predicted physical aggression symptoms significantly and negatively $(\beta=-0.18$, $\mathrm{p}<0.01)$. In the second step, variance explained increased to $8.9 \%$, and this contribution of $2.9 \%$ was statistically significant $\left(\mathrm{R}^{2}=0.09, \Delta \mathrm{F}_{1.375}=12.03, \mathrm{p}<0.01\right)$. In the third block, PC was added to the model and its contribution to the model was significant $\left(\mathrm{F}_{3.374}=12.38\right.$, $\mathrm{p}<0.01)$. After controlling for $\mathrm{EE}$ and $\mathrm{BC}$, it was seen that $\mathrm{PC}$ did not predict physical aggression symptoms at a significant level $\left(\beta_{\text {SLEES }}=0.17, \mathrm{p}<0.01 ; \beta_{\mathrm{PMS}}=-0.17\right.$, $\left.\mathrm{p}<0.01 ; \beta_{\mathrm{PCS}}=0.06, \mathrm{p}>0.05\right)$. Variance explained in the third step increased to $9 \%$, and this change of $0.3 \%$ was not significant $\left(\mathrm{R}^{2}=0.09, \Delta \mathrm{F}_{1.374}=1.09, \mathrm{p}>0.05\right)$.

When EE was added to the model in the first block for anger symptoms, its contribution to the model was significant $\left(\mathrm{F}_{1.376}=10.67, \mathrm{p}<0.01\right)$, it predicted anger symptoms significantly and positively $(ß=0.17, \mathrm{p}<0.01)$, and explained around $3 \%$ of variance in correlation $\left(\mathrm{R}^{2}=0.028\right)$. In the second block, EE was added to the model and its contribution to the model was significant $\left(\mathrm{F}_{2.375}=7.46, \mathrm{p}<0.01\right)$. After controlling for $\mathrm{PC}$, it was seen that EE predicted anger symptoms significantly $(~(=0.11 \mathrm{p}<0.01)$. Variance explained increased to around $4 \%$ in the second step, and this $1 \%$ contribution was statistically significant $\left(\mathrm{R}^{2}=0.038, \Delta \mathrm{F}_{1.375}=4.16\right.$, $\mathrm{p}<0.05)$. In the third block, $\mathrm{BC}$ was added to the model and its contribution to the model was significant $\left(\mathrm{F}_{3.374}=5.06, \mathrm{p}<0.01\right)$. After controlling for $\mathrm{PC}$ and $\mathrm{EE}$, it was seen that $\mathrm{BC}$ did not predict anger symptoms significantly and the significance level for EE was marginal $\left(\beta_{\mathrm{PCS}}=0.11, \mathrm{p}<0.05 ; \beta_{\text {SLEES }}=0.11, \mathrm{p}=0.058\right.$; $\left.\beta_{\text {PMS }}=-0.03, p>0.05\right)$. The increase of $0.1 \%$ in variance was not significant $\left(\mathrm{R}^{2}=0.039, \Delta \mathrm{F}_{1374}=0.30, \mathrm{p}>0.05\right)$.

When PC was added to the model in the first block for hostility symptoms, its contribution to the model was significant $\left(\mathrm{F}_{1.376}=29.54, \mathrm{p}<0.01\right)$, it predicted hostility symptoms significantly $(\beta=0.27, p<0.01)$ and explained around $7.3 \%$ of variance in correlation $\left(\mathrm{R}^{2}=0.073\right)$. In the second block, EE was added to the model and its contribution to the model was significant $\left(\mathrm{F}_{2.375}=15.83, \mathrm{p}<0.01\right)$. After controlling for PC, it was seen that $\mathrm{EE}$ did not predict hostility symptoms significantly $(B=0.08, p>0.01)$. In the second step, variance explained increased to around $7.8 \%$, and this rise of $0.05 \%$ was not statistically significant $\left(R^{2}=0.078\right.$, $\left.\Delta \mathrm{F}_{1.375}=2.04, \mathrm{p}>0.05\right)$. In the third block, $\mathrm{BC}$ was added 
to the model and its contribution to the model was significant $\left(\mathrm{F}_{3.374}=10.57, \mathrm{p}<0.01\right)$. After controlling for $\mathrm{PC}$ and $\mathrm{EE}$, it was seen that $\mathrm{BC}$ did not predict hostility symptoms significantly, and after adding $\mathrm{BC}$, the level of EE, too, still did not predict hostility symptoms significantly $\left(\beta_{\mathrm{PCS}}=0.24, \mathrm{p}<0.01 ; \beta_{\mathrm{SLEES}}=0.08, \mathrm{p}>0.05\right.$; $\left.\beta_{\mathrm{PMS}}=-0.02, \mathrm{p}>0.05\right)$. In the third step, there was no change in variance explained whatsoever $\left(R^{2}=0.00\right.$, $\left.\Delta \mathrm{F}_{1.374}=0.12, \mathrm{p}>0.05\right)$.

When EE was added to the model in the first block for hostility symptoms, its contribution to the model was significant $\left(\mathrm{F}_{1.376}=11.66, \mathrm{p}<0.01\right)$, it predicted hostility symptoms significantly $(\beta=0.17, \mathrm{p}<0.01)$ and explained around $3 \%$ of variance in correlation $\left(\mathrm{R}^{2}=0.03\right)$. In the second block, $\mathrm{BC}$ was added to the model and its contribution to the model was significant $\left(\mathrm{F}_{2.375}=9.17, \mathrm{p}<0.01\right)$. After controlling for $\mathrm{EE}$, it was seen that $\mathrm{BC}$ predicted verbal aggression symptoms significantly and negatively $(\beta=-0.13, \mathrm{p}<0.05)$. Variance explained in the second step increased to around $5 \%$, and this contribution of $2 \%$ was statistically significant $\left(\mathrm{R}^{2}=0.05, \Delta \mathrm{F}_{1.375}=6.51, \mathrm{p}<0.05\right)$. In the third block, PC was added to the model and its contribution to the model was significant $\left(\mathrm{F}_{3.374}=6.59, \mathrm{p}<0.01\right)$. After controlling for $\mathrm{EE}$ and $\mathrm{BC}$, it was seen that $\mathrm{PC}$ did not predict verbal aggression symptoms, and after adding PC, EE and BC still did not predict verbal aggression symptoms significantly $\left(\beta_{\text {SLEES }}=0.11, p<0.05 ; \beta_{\text {PMS }}=-0.13\right.$, $\left.\mathrm{p}<0.05 ; \beta_{P C S}=0.07, \mathrm{p}>0.05\right)$. Variance explained in the third step changed by a statistically insignificant $0.04 \%$ $\left(\mathrm{R}^{2}=0.050, \Delta \mathrm{F}_{1.374}=1.39, \mathrm{p}>0.05\right)$.

When PC was added to the model in the first block for level of general psychological symptomatology (LGPS), its contribution to the model was significant $\left(\mathrm{F}_{1.376}=42.04, \mathrm{p}<0.01\right)$, it predicted LGPS significantly and positively $(\beta=0.32, p<0.01)$ and explained around $10 \%$ of variance in correlation $\left(\mathrm{R}^{2}=0.10\right)$. In the second block, EE was added to the model, and the contribution of this variable to the model was significant $\left(\mathrm{F}_{2.375}=22.31\right.$, $\mathrm{p}<0.01)$. After controlling for $\mathrm{PC}$, it was seen that $\mathrm{EE}$ did not significantly predict LGPS $\left(\beta_{\text {SLEES }}=0.08, p>0.05\right)$. In the second step, variance explained increased to around $11 \%$ and this rise was not statistically significant $\left(\mathrm{R}^{2}=0.01, \mathrm{~F}_{1.375}=2.41, \mathrm{p}>0.05\right)$. In the third block, $\mathrm{BC}$ was added to the model and its contribution to the model was significant $\left(\mathrm{F}_{3.374}=14.98, \mathrm{p}<0.01\right)$. After controlling for $\mathrm{EE}$ and $\mathrm{PC}$, it was seen that $\mathrm{BC}$ did not predict LGPS $\left(\beta_{\mathrm{PCS}}=0.29, \mathrm{p}<0.05 ; \beta_{\mathrm{SLEES}}=0.09, \mathrm{p}>0.05 ; \beta_{\mathrm{PMS}}=0.03\right.$, $\mathrm{p}>0.05)$. Variance explained in the third step increased by a statistically insignificant $0.01 \%\left(\mathrm{R}^{2}=0.107\right.$, $\left.\Delta \mathrm{F}_{1.374}=0.389, \mathrm{p}>0.05\right)$.

\section{DISCUSSION}

This study has examined the predictive relation of EE and perceived maternal PC and BC with depressive, anxiety, aggression symptoms, and LGPS in a nonclinical university sample.

The results of our analyses show that in a nonclinical university sample, high EE correlates with higher depressive, anxiety, and aggression symptoms (physical and verbal aggression, hostility, and anger) and with a high level of psychological symptomatology.

While other available studies used different measures for EE, the results are largely similar. Almost all studies reveal that high $\mathrm{EE}$ increases internalized symptoms (8-11). Findings in the literature confirm our results for aggression symptoms. Even where the definition of aggression as used in our study was not applied, more than one study supported that high EE increases externalized symptoms (9-11). For LGPS, we did not find any studies in the literature treating this parameter in the same way we measured it in our study. However, considering that the BSI assesses internalized and externalized symptoms, we may say that the abovementioned studies support our result for level of general psychological symptomatology (8-12).

Regarding psychological control, high perceived maternal PC has been found to be related with more depressive, anxiety, aggression symptoms and higher LGPS. Findings in the literature are mostly consistent with our results.

For depressive symptoms, in line with our results many studies revealed that high perceived maternal PC significantly and positively predicts depressive and anxiety symptoms (17,23-27). While in the Turkish literature, internalized symptoms have been assessed (27), we did not find any study directly investigating depressive and anxiety symptoms. Two studies researched internalized symptoms, one of which showed that higher PC increased internalized symptoms (27), while the other one found such a correlation to be valid only for girls (22). With regard to aggression symptoms, there are studies supporting our results $(25,26,28)$ as well as those that do not (27). The difference in the study not supporting our results may originate in the failure to investigate sex differences, which might also be considered a limitation of this study. Equally, we did not find any study directly treating LGPS as a variable for PC. However, results reached by studies looking at internalized and externalized symptoms suggest that results for level of general psychological symptomatology are mostly consistent with the literature $(17,23-26,28)$. 
Of the psychological symptoms investigated, high perceived maternal BC was only found to correlate with subdimensions of high aggression, namely, high physical and verbal aggression symptoms. In the literature, we found studies that were consistent with our results for various psychological symptoms and others that were not.

For depressive symptoms, in line with our results Bean et al. (21) found that perceived maternal BC did not predict depressive symptoms. By contrast, some studies reported that perceived maternal BC negatively predicted internalized symptoms $(22,28)$. While we did not find any study treating anxiety directly as a variable, the significant correlation between depressive symptoms and anxiety symptoms $(\mathrm{r}=0.60)$ suggests that results for depressive symptoms may be partly valid for anxiety symptoms as well. Regarding aggression symptoms, results from the Turkish $(15,22)$ as well as the international literature overall support our findings; however, results differ regarding sex. While this study did not analyze aggression symptoms from the angle of sex difference, it was seen that perceived maternal BC might be protecting from externalized symptoms. We found no study directly addressing LGPS as a variable, but if we consider this complex to be made up of internalized and externalized symptoms, the aforementioned studies may also explain the results reached for LGPS.

While the behaviors considered are similar in specific respects, we found no study in the literature addressing the two concepts together. When we look at the result at the stage where our study investigated the 3 variables together, we see that this research is consistent with the findings in the literature in some respects but not in others. As we have dealt with the consistent aspects above, we will not dwell on them here to avoid repetition. Regarding the inconsistencies, the reason may be the absence of any study assessing the variables jointly, as our findings are compared with the results obtained for the variables individually.

In the light of all results, we have seen that there are common angles between EE and perceived maternal PC and $\mathrm{BC}$ in various respects. Similar to clinical samples, high EE and perceived maternal PC may constitute a risk for psychological symptoms in healthy individuals, while $\mathrm{BC}$ can be said to protect from various symptoms.

Although there are many studies in the literature done in psychiatric samples, research with non-clinical samples is limited, and the existing ones are generally examining childhood and adolescence; in Turkey, no such study has been done. From this perspective, this study can be considered a contribution to the Turkish and the general literature. The study is also relevant because it assesses two similar concepts together, parental control and EE, opening a broader perspective on the significance of the family for psychological symptoms in healthy individuals. Studies on parental control have usually been carried out in samples of children and adolescents. However, considering the importance of autonomy after adolescence (15) and the continuing, albeit somewhat reduced, parental control in our sample (29), this study may contribute to the literature a view of the family impact on psychological symptoms in healthy adults.

Apart from the contributions to the literature, there are also a number of benefits for application. While in the West, after the age of 18 years family relations weaken, the family effect continues especially in Turkish culture, and thus information about family attitude and behaviors may protect young family members from psychological symptoms. While there may not be a clinical diagnostic dimension, especially individuals from this age group present with a variety of psychological complaints where receiving detailed information about the family environment, or if needed even including the family in the therapeutic process, intervention in the family environment, and teaching the individual strategies for coping with this kind of behaviors can be relevant in order to reduce the symptoms.

Our study has a number of limitations, the first being that we only examined the maternal aspect of parental control. In addition, having recruited the sample from a single university may limit generalizability. Furthermore, we did not distinguish between the sexes according to symptoms, which might have been relevant, considering the predictable cultural differences between the behaviors of female and male children. As the instruments used were self-report forms, we need to consider the possibility that participants gave biased answers. In the light of these observations, future studies should assess parental control for mothers and fathers together, broaden the results by receiving information from mothers and fathers, too, carry out analyses for sex differences, include demographic characteristics that may affect the variables, access a sample from different regions and universities and carry out interviews to complement the self-report forms, include variables such as coping strategies, perform longitudinal studies that allow to observe the family effect in therapy, and examine this effect in different psychological symptom groups. 
To conclude, this study has been carried out to show the family effect on wellbeing and psychological symptoms of healthy individuals. Our results suggest that two of the family-related concepts, expressed emotion and perceived maternal psychological and behavioral control, may be risk factors for the development of psychological symptoms, while behavioral control may be protective against various psychological symptoms. Additional studies are needed to get a broader picture.

\begin{tabular}{|l|l|l|}
\hline \multicolumn{2}{|l|}{ Contribution Categories } & Author Initials \\
\hline \multirow{4}{*}{ Category 1} & Concept/Design & D.C., I.D. \\
\cline { 2 - 3 } & Data acquisition & D.C. \\
\cline { 2 - 3 } & Data analysis/Interpretation & D.C. \\
\hline \multirow{3}{*}{ Category 2} & Drafting manuscript & D.C. \\
\cline { 2 - 3 } & Critical revision of manuscript & D.C., I.D. \\
\hline Category 3 & Final approval and accountability & I.D., D.C. \\
\hline \multirow{2}{*}{ Other } & Technical or material support & \\
\cline { 2 - 3 } & Supervision & I.D. \\
\hline
\end{tabular}

Ethics Committee Approval: This study approval of the ethics committee of Hacettepe University, data were collected from October 2016 to January 2017.

Informed Consent: Written informed consent was obtained from the patients.

Peer-review: Externally peer-reviewed.

Conflict of Interest: The authors have declared no conflict of interests.

Financial Disclosure: There has been no funding for this research.

\section{REFERENCES}

1. Ozturk MO, Ulusahin A. Mental Health and Disorders. Twelfth ed., Ankara: Nobel Tip Kitabevi, 2015, 41.

2. Brown GW. Experiences of discharged chronic schizophrenic patients in various types of living group. Milbank Mem Fund Q 1959; 37:105-131. [CrossRef]

3. Wuerker AM. Relational control patterns and expressed emotion in families of persons with schizophrenia and bipolar disorder. Fam Process 1994; 33:389-407. [CrossRef]

4. Amaresha AC, Venkatasubramanian G. Expressed emotion in schizophrenia: an overview. Indian J Psychol Med 2012; 34:1220. [CrossRef]

5. Przeworski A, Zoellner LA, Franklin ME, Garcia A, Freeman J, March JS, Foa EB. Maternal and child expressed emotion as predictors of treatment response in pediatric obsessivecompulsive disorder. Child Psychiatry Hum Dev 2012; 43:337353. [CrossRef]

6. Wearden AJ, Tarrier N, Barrowclough C, Zastowny TR, Rahill AA. A review of expressed emotion research in health care. Clin Psychol Rev 2000; 20:633-666. [CrossRef]
7. Stubbe DE, Zahner GE, Goldstein MJ, Leckman JF. Diagnostic specificity of a brief measure of expressed emotion: a community study of children. J Child Psychol Psychiatry 1993; 34:139-154.

8. Mellick W, Kalpakci A, Sharp C. Current maternal depression moderates the relation between critical expressed emotion in mothers and depressive symptoms in their adolescent daughters. Psychiatry Res 2015;227:224-229. [CrossRef]

9. Gravener JA, Rogosch FA, Oshri A, Narayan AJ, Cicchetti D, Toth SL. The relations among maternal depressive disorder, maternal expressed emotion, and toddler behavior problems and attachment. J Abnorm Child Psychol 2012; 40:803-813. [CrossRef]

10. Hale WW, Crocetti E, Nelemans SA, Branje SJ, van Lier PA, Koot $\mathrm{HM}$, Meeus WH. Mother and adolescent expressed emotion and adolescent internalizing and externalizing symptom development: a six-year longitudinal study. Eur Child Adolesc Psychiatry 2016; 25:615-624. [CrossRef]

11. Han ZR, Shaffer A. Maternal expressed emotion in relation to child behavior problems: differential and mediating effects. J Child Fam Stud 2014; 23:1491-1500. [CrossRef]

12. Hale WW, Keijsers L, Klimstra TA, Raaijmakers QA, Hawk S, Branje SJ, Frijns T, Wijsbroek SA, van Lier P, Meeus WH. How does longitudinally measured maternal expressed emotion affect internalizing and externalizing symptoms of adolescents from the general community? J Child Psychol Psychiatry 2011; 52:1174-1183. [CrossRef]

13. Schaefer ES. Children's reports of parental behavior: an inventory. Child Dev 1965; 36:413-424. [CrossRef]

14. Barber BK. Parental psychological control: revisiting a neglected construct. Child Dev 1996; 67:3296-3319. [CrossRef]

15. Sayil M, Kindap Y, Bayar Y, Bayraktar F, Kurt D, Tigrak A, Yaban EH. Parenting and adolescent's psychosocial adaptation. Hacettepe University Yayinlari, 2012. (Turkish)

16. Abd-El-Fattah SM, Fakhroo HA. The relationship among paternal psychological control and adolescents' perfectionism and self-esteem: a partial least squares path analysis. Psychology 2012; 3:428-439. [CrossRef]

17. Pettit GS, Laird RD, Dodge KA, Bates JE, Criss MM. Antecedents and behavior-problem outcomes of parental monitoring and psychological control in early adolescence. Child Dev 2001; 72:583-598. [CrossRef]

18. Nanda MM, Kotchick BA, Grover RL. Parental psychological control and childhood anxiety: the mediating role of perceived lack of control. J Child Fam Stud 2012; 21:637-645. [CrossRef]

19. Tu YC, Lee H, Chen HY, Kao TF. A study on the relationships among psychological control, adolescent depression, and antisocial behavior in Taiwan. Procedia Soc Behav Sci 2014; 122:335-343. [CrossRef]

20. Barber BK, Olsen JE, Shagle SC. Associations between parental psychological and behavioral control and youth internalized and externalized behaviors. Child Dev 1994; 65:1120-1136. [CrossRef]

21. Bean RA, Barber BK, Crane DR. Parental support, behavioral control, and psychological control among African American youth. The relationships to academic grades, delinquency, and depression. J Fam Issues 2006; 27:1335-1355. [CrossRef] 
22. Kindap Y, Sayil M, Kumru A. The relationships among type of perceived maternal control, psychosocial adjustment, and friendship in adolescence: the mediator role of self-esteem. Turkish Journal of Psychology 2008; 23:92-111. (Turkish)

23. Garber J, Robinson NS, Valentiner D. The relation between parenting and adolescent depression: self-worth as a mediator. J Adolescent Research 1997; 12:12-33. [CrossRef]

24. Bradford K, Barber BK, Olsen JA, Maughan SL, Erickson LD, Ward D, Stolz HE. A multi-national study of interparental conflict, parenting, and adolescent functioning: South Africa, Bangladesh, China, India, Bosnia, Germany, Palestine, Colombia, and the United States. Marriage Fam Rev 2004; 35:107-137.

25. Loukas A, Paulos SK, Robinson S. Early adolescent social and overt aggression: examining the roles of social anxiety and maternal psychological control. J Youth Adolesc 2005; 34:335345. [CrossRef]

26. Kuppens S, Grietens H, Onghena P, Michiels D. Relations between parental psychological control and childhood relational aggression: reciprocal in nature? J Clin Child Adolesc Psychol 2009; 38:117-131. [CrossRef]

27. Nelson DA, Crick NR. Parental psychological control: implications for childhood physical and relational aggression: In Barber BK (editor). Intrusive Parenting: How Psychological Control Affects Children and Adolescents. Washington DC: American Psychological Association, 2002, 16:161-189. [CrossRef]

28. Tepe YK, Sayil M. The mediating role of relational aggression in the relationship between parental control and social functioning of the adolescent. Turkish Journal of Psychology 2012; 27:119137. (Turkish)

29. Dogan A, Cebioglu S. Emerging adulthood: a period between adolescence and adulthood. Turk Psikoloji Yazilari 2011; 14:1121. (Turkish)

30. Cap D. Expressed Emotion and Parental Control as a Predictor of Psychological Symptoms. Unpublished Master's Thesis, Hacettepe University Arts and Humanities Faculty, Department of Psychology, Ankara, 2017. (Turkish)

31. Beck AT, Ward CH, Mendelson M, Mock J, Erbaugh J. An inventory for measuring depression. Arch Gen Psychiatry 1961; 4:561-571. [CrossRef]
32. Hisli N. A study on the validity of the Beck Depression Inventory. Studies in Psychology 1988; 6:118-126. (Turkish)

33. Beck AT, Epstein N, Brown G, Steer RA. An inventory for measuring for clinical anxiety: psychometric properties. J Consult Clin Psychol 1988; 56:893-897. [CrossRef]

34. Ulusoy M, Sahin NH, Erkmen H. Turkish version of the Beck anxiety inventory: psychometric properties. J Cogn Psychother $1998 ; 12: 163-172$.

35. Derogatis LR. The brief symptom inventory (BSI), administration, scoring and procedures manual. II. Clinical Psychometric Research Inc 1992; 12:12-33.

36. Sahin NH, Durak A. Brief Symptom Inventory-BSI: adaptation for Turkish youths. Turkish Journal of Psychology 1994: 9:44-56. (Turkish)

37. Buss AH, Perry M. The aggression questionnaire. J Pers Soc Psychol 1992; 63:452-459. [CrossRef]

38. Demirtas-Madran HA. The reliability and validity of the BussPerry Aggression Questionnaire (BAQ)-Turkish version. Turk Psikiyatri Derg 2013; 24:124-129. (Turkish) [CrossRef]

39. Nelis SM, Rae G, Liddell C. The level of expressed emotion scale: a useful measure of expressed emotion in adolescents? J Adolesc 2011; 34:311-318. [CrossRef]

40. Vural P, Sigirli D, Eray S, Ercan, I, Kilic E. The reliability and validity of expressed emotion scale in adolescents. Turkiye Klinikleri 2013; 33:191-199. (Turkish) [CrossRef]

41. Barber BK, Olsen JA, Hunter SB, Schluterman JM, McNeely C, Bose K. Refining the measurement of parental control: integrating input from adolescents. Society for Research in Child Development Conference, 2007.

42. Sayil M, Kindap Y. Turkish adaptation of the Parental Psychological Control Scale(s): a study of validity and reliability. Turk Psikoloji Yazilari 2010; 13(25):62-71. (Turkish)

43. Kerr M, Stattin H. What parents know, how they know it, and several forms of adolescent adjustment: further support for reinterpretation of monitoring. Dev Psychol 2000; 36:366-380.

44. Tabachnick BG, Fidell LS. Using multivariate statistics. Pearson, 2001. 